\title{
eJRIEPS
}

Ejournal de la recherche sur l'intervention en éducation physique et sport

15 | 2008

Varia

\section{Hommage à Alain Durey}

\section{Floriane Durey}

Édition électronique

URL : https://journals.openedition.org/ejrieps/5798

DOI : 10.4000/ejrieps.5798

ISSN : 2105-0821

\section{Éditeur}

ELLIADD

\section{Référence électronique}

Floriane Durey, « Hommage à Alain Durey », eJRIEPS [En ligne], 15 | 2008, mis en ligne le 01 juillet 2008, consulté le 03 mai 2021. URL : http://journals.openedition.org/ejrieps/5798 ; DOI : https:// doi.org/10.4000/ejrieps.5798

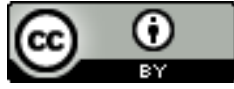

La revue eJRIEPS est mise à disposition selon les termes de la Creative Commons Attribution 4.0 International License. 


\section{Hommage à Alain Durey}

\section{Floriane Durey}

J'ai dû aller me promener dans la nature pour trouver l'inspiration et écrire ce texte sur mon père. Pincée par le froid et chauffée par le soleil d'automne, c'était le cadre idéal pour réfléchir à cet hommage qui me remplit de chaleur car il se présente une occasion de penser encore à Alain. Mais, cela n'est pas sans être difficile, un peu comme ce froid qui s'est installé pour nous depuis sa disparition. Toujours est-il que Ghislaine, sa femme, Lilian, son fils, ses parents et son frère se joignent à moi pour vous remercier d'avoir dédié ces journées didactiques à Alain Durey.

En vous voyant ici tous réunis, c'est un peu de mon père qui ressurgit car la recherche était une grande partie de sa vie, vie que vous avez partagée aussi en tant qu'amis. Vous ne le savez peut-être pas, mais vous avez peuplé l'enfance de Lilian et la mienne : anecdotes, rigolades, problèmes financiers de chercheurs, affection réelle, Toulousains à la maison le temps d'un colloque : Philippe, Chantal, Jean-Louis, Jean-Pierre, Daniel, Jean-François, André, Jackye. Mon père voyait en chacun de vous un collègue, mais aussi un ami, à tel point qu'avant d'intégrer moi-même le milieu professionnel, je pensais que c'était la règle.

C'est à vous donc que j'avais envie de rendre cet hommage. Je pense qu'il doit vous manquer à la fois en tant que chercheur : je n'ai pas son humilité alors je peux me permettre de dire qu'il avait l'air d'être brillant. Mais aussi en tant qu'individu, qui était décrit de façon si touchante par Michel Laurent et Roger Journeaux dans le Bulletin des Ecoles Normales Supérieures.

Pour ma part, j'ai l'image d'un homme tranquille, grâce en partie à ses racines. II s'est effectivement toujours nourri du Sud-Ouest (au sens propre et figuré). II avait une grande gentillesse et cette grande qualité qu'est la bienveillance. Humble enfin, il se faisait apprécier aussi pour cela, par ceux qui font réellement de la recherche.

Lorsque je vous disais que la recherche était intégrée à sa vie, en l'occurrence nous, c'est que nous en étions la cible au quotidien. II faut savoir que lorsque l'un de nous trois posait une question simple à Alain, il débutait par une thèse, suivie de son antithèse et enfin de l'attendue synthèse. Cela m'a appris à la fois à répondre seule à certaines questions, mais 
aussi à intégrer cette façon méthodologique d'envisager toute chose. Heureusement quand même que ma mère et la danse sont passées devant lui.

Ce que j'aimais aussi beaucoup chez lui, c'est qu'il savait à la fois être sérieux et très drôle. II avait beaucoup d'humour et pratiquait l'autodérision. II y avait ce même décalage entre sa vie et la volonté de faire carrière, qui n'a jamais été un objectif en soi pour lui. Alain aimait surtout chercher, s'éprouver, aller jusqu'au bout de ce dont il était capable. II n'attendait aucune reconnaissance, se connaissant suffisamment lui-même.

Cet hommage peut apparaître à bien des égards tel un éloge d'une fille qui n'aurait pas résolu son complexe d'Oedipe mais il n'en est rien. La disparition des êtres chers fait simplement grandir et je sais que beaucoup d'entre vous reconnaîtront à travers ce portrait un Alain qu'il a bien connu lui-même. 